\title{
Dental Anomalies in Permanent Teeth after Trauma in Primary Dentition
}

\author{
Elena Bardellini */Francesca Amadori **/Stefania Pasini ***/Alessandra Majorana ****
}

\begin{abstract}
Objective: This retrospective study aims to evaluate the prevalence of dental anomalies in permanent teeth as a result of a trauma concerning the predecessor primary teeth. Study design: A total of 241 records of children $(118$ males and 123 females, mean age $3.62 \pm 1.40)$ affected by trauma on primary teeth were analyzed. All patients were recalled to evaluate the status of the permanent successor teeth by clinical and radiographic investigations. Results: Out of 241 patients, 106 patients (for a total of 179 traumatized primary teeth) presented at the recall. Dental anomalies on successor permanent teeth were detected in 21 patients $(19.8 \%)$, for a total of 26 teeth (14.5\%) and 28 anomalies. Anomalies of the eruptive process were the most observed disturbances (60.7\%), followed by enamel hypoplasia (25\%) and white spots (14.3\%). A higher percentage of anomalies on permanent teeth was observed when trauma occurred at an age less than 36 months $(38.5 \%$ of cases). Intrusive and extrusive luxation were related with the most cases of clinical disturbances in the successor permanent teeth. Conclusions: The results of this study highlight the risk of dental anomalies after a trauma in primary dentition, especially in early-aged children and in case of intrusive luxation.
\end{abstract}

Key words: Primary teeth, trauma, sequelae, hypoplasia, delayed eruption

\section{INTRODUCTION}

$\mathrm{D}$ ental trauma in primary dentition may have serious medical, aesthetic, and psychological consequences. The main issue is that traumatic injuries of primary teeth have the potential to damage the correspondent permanent teeth for the close relation between the apices of the primary teeth and the germs of their successors. ${ }^{1,2}$ Epidemiological studies have shown a frequency of trauma in primary dentition approximately of $30 \% \cdot^{2-4}$ The highest prevalence of trauma in primary dentition can be observed in children under 2 years and the most frequently involved teeth are the primary upper incisors. ${ }^{5,6}$

\footnotetext{
*Elena Bardellini , 'Department of Paediatric Dentistry, Dental School, University of Brescia, Brescia, Italy

**Francesca Amadori, ${ }^{1}$ Department of Paediatric Dentistry, Dental School, University of Brescia, Brescia, Italy.

***Stefania Pasini, Spedali Civili di Brescia, Dental Clinic, Brescia, Italy.

****Alessandra Majorana 'Department of Paediatric Dentistry, Dental School, University of Brescia, Brescia, Italy
}

Send all Correspondence to:

Elena Bardellini

p.le Spedali Civili 1

25133 Brescia, Italy.

Phone : 00393996521

Fax : 0039030303194

E-mail: bardelena@libero.it
There are two main mechanisms about how a dental trauma on primary teeth can damage the permanent successors: firstly, a direct injury of the germ of the permanent tooth for the impact of the apex of the primary tooth's root and, secondly, an indirect injury due to the pulp necrosis of the primary tooth and the consequent periapical infection. ${ }^{1,2}$ Traumatic avulsion and intrusive luxation in primary dentition are considered the main causes of damage in permanent successors. ${ }^{7-11}$ This occurrence is common, varying from 19 $\%$ to $69 \%$. ${ }^{12,13}$

The most frequent consequences in permanent dentition include white or yellow opacity, enamel hypoplasia, crown dilaceration, root angulation, arrest of root development and eruption disturbance. ${ }^{14-16}$ These anomalies may vary from enamel hypocalcification to arrest of the permanent bud's growth, according to the stage of development and maturation of both the traumatized primary tooth and the correspondent permanent germ and to the intensity and direction of the trauma itself. ${ }^{6-9,16}$ Crown dilacerations are more common between 1.5 and 3.5 years of age, while root malformation between 4 and 5 years of age. ${ }^{16}$ The purpose of this study was to investigate the prevalence of dental anomalies in permanent teeth after a trauma concerning their predecessors. 


\section{MATERIALS AND METHOD}

A retrospective study was performed in order to observe the effects of dental trauma in primary dentition on permanent successors in terms of dental anomalies.

A total of 1740 records of children with dental trauma referred to the Traumatology Department of the Dental Clinic of the University of Brescia were analyzed. The criteria for inclusion in the study were: age $<5$ years at the moment of trauma; location of the trauma on the anterior primary teeth; no medical history of infectious disease, coeliac disease, syndromes, chemo-radio therapy, immunosuppressant drugs or any other medication with a known effect on the dental development. A total of 241 records of children met the criteria of the study. Data about age of the patient at the time of trauma, cause of trauma, traumatized primary teeth and type of trauma were collected.

All patients were recalled to evaluate the status of the permanent successors. All children's parents gave informed consent according to the recommendations of the declaration of Helsinki. Ethical approval for the research was granted by the Dental School Research Ethics Committee (DSREC). The clinical evaluation of the permanent teeth was performed by the same two examiners (E.B, F.A.). All subjects were placed in a dental chair. Their teeth were cleaned with an abrasive paste, washed, dried, and then observed in good artificial light, a small mirror, and a probe. History of the permanent teeth from trauma to the follow-up (eruption time: normal, delayed, early; other dental trauma; pain) was recorded. An intra-oral visit, including an X-ray examination, was performed in order to observe possible dental anomalies (i.e. discolorations, enamel hypoplasia, crown/root malformations, disturbances in eruption). All dental anomalies were noted and photographed.

\section{Data analysis}

The data were imputed in an electronic datasheet (Microsoft Excel $\left.{ }^{\circledR}\right)$ and then analyzed. Initially, the categorization of type of trauma was counted and the percentage for each variable was determined. Secondly, the association between the different variables was evaluated and difference between groups was evaluated by $\chi^{2}$ test or Fischer's exact test when the value in cell was less than 5. STATA statistical data analysis software (Version 8.2, Stata Corporation, College Station, Texas USA) was used. The level of significance was established at $\mathrm{p}<0.05$.

\section{RESULTS}

Two hundred forty-one records of patients affected by dental trauma on primary teeth were studied to obtain information. The sample was composed by 118 males and 123 females (mean age $3.62 \pm 1.40$, age range 10 months- 6 years), for a total of 406 teeth.

Upper central incisors resulted the most frequently traumatized teeth $(65.7 \%)$ followed by upper right lateral incisors (19.0\%), upper left lateral incisors (12.1\%), and the other teeth $(3.2 \%)$. Regarding the types of trauma, the most frequent was intrusive luxation $(20.7 \%)$, followed by extrusive luxation (15.8\%), concussion (15.8\%) and lateral luxation (15.4\%). Traumatic avulsion, root/crown fracture and subluxation occurred in $11.1 \%$ of cases. Types of trauma and distribution according affected teeth are shown in Table 1 .

All patients were recalled to evaluate the status of the permanent teeth corresponding to the traumatized primary teeth. Only 106 patients (mean age 8.32 1.40 years, age-range 7-11 years) presented at the follow up visit. The sample was composed by 55 males and 51 females for a total of 179 permanent teeth. Dental anomalies were observed in 21 patients, for a total of 26 permanent teeth, in detail 12 (46.1\%) left central incisors, $9(34.6 \%)$ right central incisors, 4 left lateral incisors and $1(3.8 \%)$ right lateral incisor.

The association between the age of the child at the moment of the trauma and the presence of dental anomalies in permanent teeth is shown in Table 2. The results indicate a high prevalence of disturbances in children under 36 months. The highest percentages of anomalies on permanent teeth were observed when trauma occurred at an age less than 24 months (23.1\% of cases) and at an age between 37 and 48 months ( $26.9 \%$ of cases).

As concerns the type of anomalies on the 26 permanent teeth, 11 structural anomalies (7 enamel hypoplasia and 4 white spots) and 17 anomalies of the eruptive process (7 delayed eruptions, 7 early eruptions, 2 malposition, 1 inclusion) were observed. All of them were located on the upper central incisors. One upper central incisor suffered by three different types of anomaly simultaneously: 2 structural anomalies and 1 malposition.

The relation between type of injury on primary teeth and type of dental anomalies on permanent teeth is shown in Fig.1. Intrusive luxation was the type of trauma most associated with the presence of alteration in the permanent teeth (10/34), followed by extrusive luxation (10/38). Only concussion and subluxation resulted never having caused any anomaly on permanent tooth. Among 7 cases of enamel hypoplasia, 6 were consequences of intrusive luxations and one of lateral luxation; white spots were observed in case of intrusive luxations ( 2 cases) and extrusive luxations (2 cases). Among 7 cases of delayed eruptions, 4 depended on traumatic avulsions and 3 on extrusive luxations; early eruptions occurred as sequelae of extrusive luxations (5 cases) and lateral luxations ( 2 cases). Malpositions were observed in case of intrusive (1 case) and lateral luxation (1 case). Inclusion occurred once in case of intrusive luxation.

\section{DISCUSSION}

This study was carried out to investigate the relationship between dental trauma on primary teeth and possible anomalies of their successors. There are only few statistical studies $^{16,17,19-21}$ on wide samples of patients about the damage on permanent teeth after a trauma on the primary teeth, most likely because of the difficult follow up for the long period of time between the traumatic event on the primary teeth and the eruption of their successors. In our experience, the parents show great concern when the trauma occurs, for the prognosis of the primary and permanent teeth. Once their initial anxiety 
Table 1. Types of trauma in primary dentition and their distribution according affected teeth (number and percentage).

\begin{tabular}{|c|c|c|c|c|c|c|}
\hline & $\begin{array}{l}\text { Right Cent } \\
\text { upper incisor }\end{array}$ & $\begin{array}{c}\text { Right Lat } \\
\text { Upper incisor }\end{array}$ & $\begin{array}{c}\text { Left Cent } \\
\text { upper incisor }\end{array}$ & $\begin{array}{c}\text { Left Lat } \\
\text { Upper incisor }\end{array}$ & Others teeth & Total \\
\hline & $n(\%)$ & n (\%) & n (\%) & n (\%) & n (\%) & n (\%) \\
\hline Intrusive luxation & $32(38.1)$ & $11(13.1)$ & $27(32.1)$ & $14(16.7)$ & $0(0.0)$ & $84(20.7)$ \\
\hline Lateral luxation & $20(33.9)$ & $10(16.9)$ & $18(30.5)$ & $9(15.3)$ & $2(3.4)$ & 59 (15.4) \\
\hline Extrusive luxation & $21(32.8)$ & $12(18.8)$ & $24(37.5)$ & $5(7.8)$ & $2(3.1)$ & $64(15.8)$ \\
\hline Traumatic avulsion & $15(33.3)$ & $10(22.2)$ & $11(24.4)$ & $6(13.4)$ & $3(6.7)$ & 45 (11.1) \\
\hline Root/crown fracture & $13(28.9)$ & $10(22.2)$ & $17(37.8)$ & $3(6.7)$ & $2(4.4)$ & $45(11.1)$ \\
\hline Concussion & $18(28.1)$ & $15(23.4)$ & $22(34.4)$ & $7(11.0)$ & $2(3.1)$ & $64(15.8)$ \\
\hline Subluxation & $16(35.6)$ & $9(20.0)$ & $13(28.9)$ & $5(11.1)$ & $2(4.4)$ & 45 (11.1) \\
\hline Total & 135 (33.2) & $77(19.0)$ & $132(32.5)$ & $49(12.1)$ & $13(3.2)$ & 406 \\
\hline
\end{tabular}

Table 2. Association between the age at the moment of the trauma and the presence of dental anomalies in permanent dentition.

\begin{tabular}{lccc}
\hline $\begin{array}{c}\text { Age of trauma } \\
\text { (months) }\end{array}$ & $\begin{array}{c}\text { Patients } \\
n(\%)\end{array}$ & $\begin{array}{c}\text { Traumatized } \\
\text { primary teeth } \\
n(\%)\end{array}$ & $\begin{array}{c}\text { Permanent teeth } \\
\text { with dental anomalies } \\
n(\%)\end{array}$ \\
\hline less than 24 & $21(19.8)$ & $35(19.6)$ & $6(23.1)$ \\
$25-36$ & $22(20.7)$ & $40(22.3)$ & $4(15.4)$ \\
$37-48$ & $18(17.0)$ & $30(16.8)$ & $7(26.9)$ \\
$49-60$ & $18(17.0)$ & $30(16.8)$ & $3(11.5)$ \\
$>61$ & $27(25.5)$ & $44(24.5)$ & $6(23.1)$ \\
Total & $106(100.0)$ & $179(100.0)$ & $26(100.0)$ \\
\hline
\end{tabular}

Fig. 1 Relation between type of trauma on primary teeth and type of anomalies $(n=28)$ on permanent teeth.

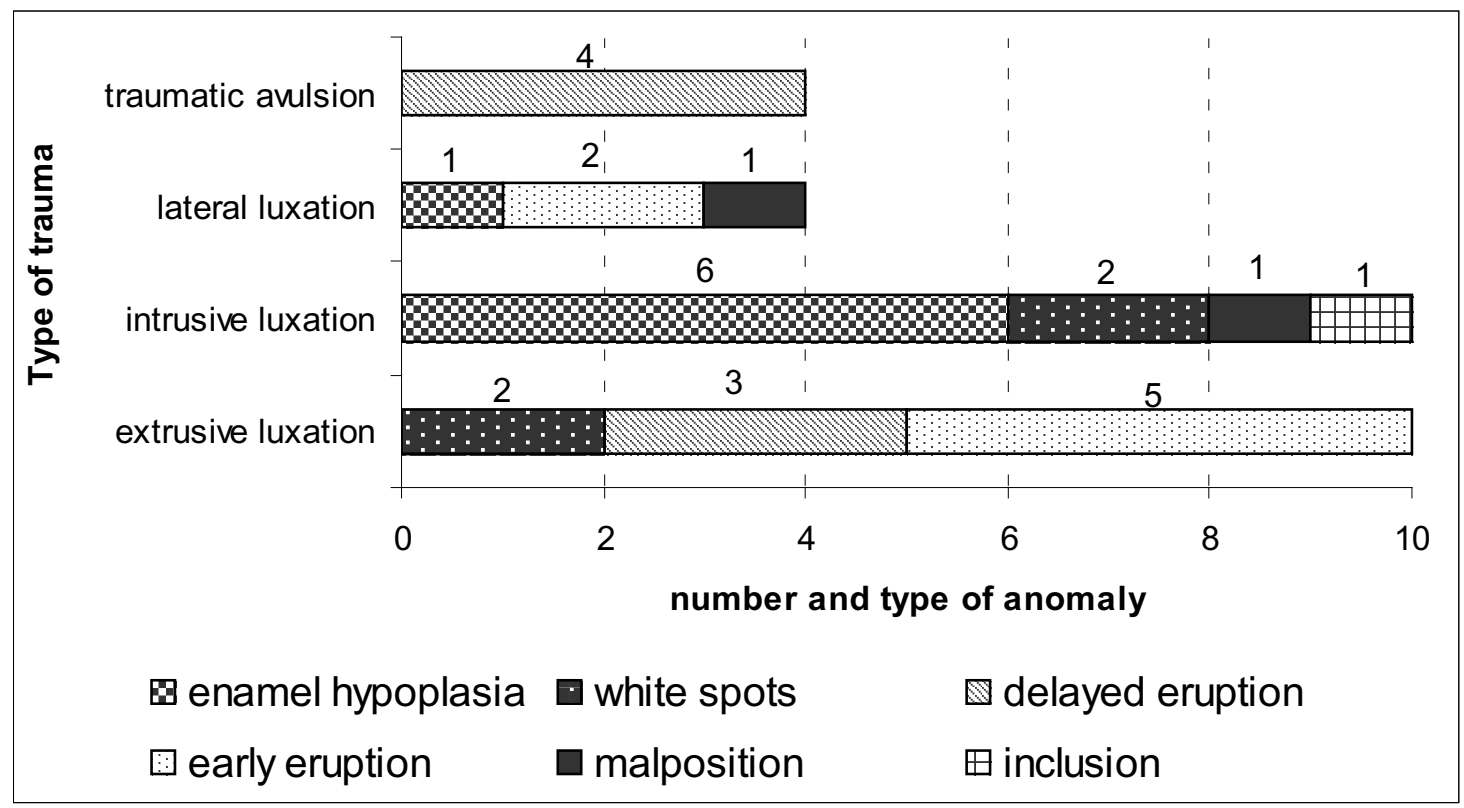


calms down, their attention fades away and it is difficult to convince them to come back for the follow up visit. A similar situation was observed by Da Silva Assunção², reporting a loss of more than $50 \%$ of patients for the clinical assessment and by Brin ${ }^{13}$, relating a low response of the recalls to a lesser severity of dental sequalae of trauma or to dental awareness of the patients. Despite these difficulties, the number of examined permanent teeth in this study $(n=179)$ can be considered significant.

This investigation was carried out on 106 patients reporting injuries in primary dentition. Anomalies on permanent teeth were observed in $19.8 \%$ of them, for a total of $26 / 179$ permanent teeth $(14.5 \%)$ and 28 dental anomalies. These results are in the lower limit of the reported range of percentage (12-74\%) of permanent teeth with developmental disturbances due to injuries of their predecessors. ${ }^{14}$

Anomalies of the eruptive process were the most observed disturbances in permanent teeth $(60.7 \%)$, followed by enamel hypoplasia with yellow-brown discoloration and white spot (39.3\%).Contrary to other studies, no crown dilacerations or root angulations were detected. ${ }^{2,17}$ In agreement with many Authors ${ }^{2-6,12-19}$, intrusive and extrusive luxations of primary teeth resulted the most frequent causes of anomalies on permanent teeth. In fact, out of 28 cases of anomalies on permanent teeth, $36 \%(n=10)$ of them were caused by intrusive luxations and another $36 \%(n=10)$ of them by extrusive luxations of the predecessors. Enamel hypoplasia resulted quite exclusively associated with intrusive luxation while delayed eruption with extrusive luxation and traumatic avulsion.

Intrusive luxation of a primary tooth bears the highest risk of damaging the permanent tooth germ ${ }^{14,19,22}$ because of their close anatomic relationship with the apices of the primary incisors. ${ }^{1,12,23}$ In a cephalometric study ${ }^{24}$, the thickness of the hard tissue barrier between primary incisors and their successors was found to be $<3 \mathrm{~mm}$, a data which could help to understand the potential disruptive effect on permanent tooth germs during odontogenesis. Unexpectedly, extrusive luxation was the second most frequent cause of dental anomalies in permanent teeth while traumatic avulsion caused sequelae only in $4 / 29$ cases. About $85,7 \%$ of eruption disturbances (12/14 cases) occurred in case of extrusive luxation and traumatic avulsion. Extrusive luxation is a partial displacement of the tooth out of its socket, with palatal gingival fibers preventing the tooth from being avulsed. One can therefore assume a mechanism of damage to the germs of permanent teeth similar to that for traumatic avulsion, well described by Andreasen and Ravn. ${ }^{17,25}$ The root curvature of the primary tooth may provoke a slight rotation movement during the trauma, which can injure the buds of the successor permanent tooth. ${ }^{25}$ Furthermore, since the treatment of the extrusive luxation is most of the times the extraction, the premature ossification favoring eruption disturbances is at all similar to that of traumatic avulsion.
The age of the child at the time of sustained trauma is another major point of concern. Various studies report a higher percentage of anomalies on permanent teeth in patients younger than 2 years at the time of trauma. , $17,19,26-28^{2}$ This is owing to the fact that germs of the incisors are particularly sensitive in the early stages of their development, which occurs between the ages of 4 months and 4 years. ${ }^{12,17,19}$ At this critical time, injury or inflammatory changes can interfere with the different levels of odontogenesis, such as morphodifferentiation, organization, mineralization, or the final pre eruptive maturation. The results of this study show a higher susceptibility of children younger than 24-36 months $(38.5 \%)$ to present anomalies in the developing of permanent teeth. Moreover, correlating the age at the time of trauma to the type of detected anomalies, enamel hypoplasia and white spots were observed in younger age groups while they were not present in children who suffered dental trauma at age over 49 months. This result is in agreement with other studies which report the presence of hypoplasia in children aged 1 to 3 years at the time of trauma, possibly imputable to the completion of the formation of the crown which occurs usually within three years. ${ }^{7-9}$

Eruption failure or delay, ectopic eruption, and misalignment of permanent incisors are also possible outcomes following traumatic injuries to their predecessors. Alterations in the eruption process resulted the most common anomalies on permanent teeth, representing $60.7 \%$ of all observed disturbances. These condition may arise from the physical displacement of the permanent germ (with or without dilaceration), the abnormal changes that might occur in the connective tissue overlying the permanent tooth, formation of thick/fibrous gingiva, and lack of eruption guidance from the prematurely lost primary incisor ${ }^{12,14}$.

\section{CONCLUSIONS}

The results of this investigation emphasize the special attention required for children who suffer dental trauma at early ages (up to 3 years), especially in cases of intrusive luxation. Therefore it is important to inform the parents at the moment of trauma about the possible effects upon developing teeth and also to perform a rigorous follow up examination to detect timely possible abnormalities. 


\section{REFERENCES}

1. Flores MT. Traumatic injuries in the primary dentition. Dent Traumatol 18: 287-298, 2002.

2. Da Silva Assunção LR, Ferelle A, Iwakura ML, Cunha RF. Effects on permanent teeth after luxation injuries to the primary predecessors: a study in children assisted at an emergency service. Dental Traumatol 25: 165-170, 2009.

3. Andreasen JO, Ravn JJ. Epidemiology of traumatic dental injuries to primary and permanent teeth in a Danish population sample. Int J Oral Surg 1:235-239, 1972.

4. Kramer PF, Zembruski C, Ferreira SH, Feldens CA. Traumatic dental injuries in Brazilian preschool children. Dent Traumatol 19: 299-303, 2003.

5. Cunha RF, Pugliesi DM, Mello Vieira AE. Oral trauma in Brazilian patients aged 0-3 years. Dent Traumatol 17:210-212, 2001.

6. Cardoso M, de Carvalho Rocha MJ. Traumatized primary teeth in children assisted at the Federal University of Santa Catarina, Brazil. Dent Traumatol 18:129-133, 2002.

7. Diab M, el Badrawy HE. Intrusion injuries of primary incisors. Part I. Review and management. Quintessence Int 31: 327-334, 2000.

8. Diab M, el Badrawy HE. Intrusion injuries of primary incisors. Part II. Sequelae affecting the intruded primary incisors. Quintessence Int 31:335-341, 2000.

9. Diab M, el Badrawy HE. Intrusion injuries of primary incisors. Part III. Effects on the permanent successors. Quintessence Int 31: 377-384,2000.

10. Garcia-Godoy F, Pulver F. Treatment of trauma to the primary and young permanent dentitions. Dent Clin North Am 44: 597-632, 2000.

11. Holan G, Ram D. Sequelae and prognosis of intruded primary incisors: a retrospective study. Pediatr Dent 21:242-247, 1999.

12. Andreasen JO, Flores M. Injuries to developing teeth. In: Andreasen JO, Andreasen FM, Andersson L, editors. Textbook and color atlas of traumatic injuries to the teeth. $4^{\text {th }}$ ed. Oxford (UK): Blackwell Munksgaard; 542-576, 2007.

13. Brin I, Fuks A, Ben Bassat Y, Zilberman Y. Trauma to primary incisors and its effect on the permanent successors. Pediatr Dent 6: 78-82,1984.

14. Güngör HC, Püşman, Uysal S. Eruption delay and sequelae in permanent incisors following intrusive luxation in primary dentition: a case report. Dental Traumatol 27: 156-158, 2011.

15. Andreasen JO. The influence of traumatic intrusion of primary teeth on their permanent successors. A radiographic and histologic study in monkeys. Int J Oral Surg 5: 207-19, 1976.
16. von Arx T. Developmental disturbances of permanent teeth following trauma to the primary dentition. Aust Dent J 38:1-10, 1993.

17. Andreasen JO, Ravn JJ. The effect of traumatic injuries to primary teeth on their permanent successors. II. A clinical and radiographic follow-up study of 213 teeth. Scand J Dent Res 79:284-94, 1971.

18. Mielnik-Blaszczak M, Pulawska J, Tomankiewicz M. Distant consequences of traumatic injuries to primary teeth- a case report. Ann Univ Mariae Curie Sklodowska Med 59:76-79, 2004.

19. Seenhenn-Kirchner S, Jacobs H-G. Traumatic injuries to the primary dentition and effects on the permanent successors- a clinical follow-up study. Dent Traumatol 22:237-241, 2006.

20. Borum MK, Andreasen JO. Sequelae of trauma to primary maxillary incisor. Part I. Complications in the primary dentition. Endod Dent Traumatol 14:206-209, 1998.

21. Christophersen P, Freund M, Harild L. Avulsion of primary teeth and sequelae on the permanent successors. Dent Traumatol 21: 320-323, 2005.

22. Colak I, Markovic D, Petrovic B, Peric T, Milenkovic A. A retrospective study of intrusive injuries in primary dentition. Dent Traumatol 25 : 605-610, 2009.

23. McTigue DJ. Managing injuries to the primary dentition. Dent Clin North Am 53:627-638, 2009.

24. Smith RJ, Rapp R. A cephalometric study of the developmental relationship between primary and permanent maxillary central incisor teeth. ASDC J Dent Child 47:36-41, 1980.

25. Ravn JJ. Developmental disturbances in permanent teeth after exarticulation of their primary predecessors. Scand J Dent Res 83:131-134, 1975.

26. Tsilingaridis G, Malmgren B, Andreasen JO, Malmgren O. Intrusive luxation of 60 permanent incisors: a retrospective study of treatment and outcome. Dent Traumatol 28: 416-422, 2012.

27. Higgins JPT, Green S, editors. Cochrane handbook for systematic reviews of interventions, version 5.1.0 [updated March 2011]. The Cochrane Collaboration, 2011. Available at: http://www.cochrane-handbook.org.

28. Wigen TI, Agnalt R, Jacobsen I. Intrusive luxation of permanent incisors in norwegians aged 6-17 years: a retrospective study of treatment and outcome. Dent Traumatol 24:612-618, 2008. 